\title{
MORPHO-MOLECULAR CHARACTERIZATION AND SCREENING OF RICE (Oryza sativa l.) GENOTYPES FOR SALINITY TOLERANCE AT SEEDLING STAGE
}

\author{
S.A.A. Muti ${ }^{1}$, M.I. Hoque ${ }^{2 *}$, M.M. Islam ${ }^{3}$, M.A. Siddique ${ }^{4}$ and M.S. Islam ${ }^{5}$ \\ ${ }^{1 \& 5}$ Department of Biotechnology, Bangladesh Agricultural University (BAU), \\ Mymensingh-2202, Bangladesh \\ ${ }^{2 *}$ Plant Breeding Division, Bangladesh Institute of Nuclear Agriculture (BINA), BAU \\ Campus, Mymensingh-2202, Bangladesh, \\ ${ }^{3}$ Biotechnology Division, Bangladesh Institute of Nuclear Agriculture (BINA), BAU \\ Campus, Mymensingh-2202, Bangladesh, \\ ${ }^{4}$ GRSD, Bangladesh Rice Research Institute (BRRI), Gazipur-1701, Bangladesh
}

\begin{abstract}
Salinity is one of the major abiotic stresses which severely affect the production of crops across the world. Twenty rice genotypes of diverse origins were assessed to examine salt tolerance potentiality at seedling stage as well as to elucidate the genetic variation using SSR markers. Consequently, IRRI standard protocol was applied to screen out those varieties for tolerance at the glasshouse laboratory of Bangladesh Institute of Nuclear Agriculture, maintaining salt stress level at $6 \mathrm{dS} \mathrm{m} \mathrm{m}^{-1}, 8 \mathrm{dS} \mathrm{m} \mathrm{m}^{-1}, 10 \mathrm{dS} \mathrm{m}^{-1}$ and $12 \mathrm{dS} \mathrm{m}^{-1}$. Data on morphological parameter were recorded as shoot length $(\mathrm{cm})$, root length $(\mathrm{cm})$ and total dry matter (TDM). For molecular characterization thirteen SSR markers were exploited to determine the genetic diversity and in this context, 53alleles were revealed while the mean number of alleles per locus was 4.The Polymorphism Information Content (PIC) value ranged from 0.370.78 having an average of 0.58 . The Un-weighted Pair Group Method with Arithmetic Mean (UPGMA) displayed three major clusters including some sub-clusters, where in Cluster 1, Binadhan8, Binadhan-10, Pokkali and FL478 were very close in their vicinity. Information obtained from this experiment, thus can be taken into account for stress breeding program and prospective genetic materials could be utilized for exploring the genetic architecture in favor of salt tolerance as well as for developing better salt tolerant rice varieties in near future.
\end{abstract}

Keywords: Rice, Abiotic stress, Salinity, Tolerance, SSR marker, Diversity, Polymorphism

"Corresponding author: apu.pstu@gmail.com 


\section{INTRODUCTION}

Rice (O. sativa) is the staple food of an estimated 3.5 billion people throughout the world. Nowadays, rice is produced in every continent of the world except the Antarctica. Thousands of rice cultivars are cultivated across 100 countries (IRRI, 2013). However, worldwide, different biotic and abiotic stresses (drought, flood, salinity) are responsible for the stagnant production of rice (Shelly et al., 2016). Salinity is one of the major hindrances to increase rice production worldwide. Onefifth of the irrigated arable lands are recorded to be severely affected by high salinity throughout the world (Negrao et al., 2011). Bangladesh has a considerable amount of coastal areas that are affected to salinity and occupies $30 \%$ of net cultivable land (Mamun et al., 2019). Coastal land of Bangladeshis affected by varying degrees of salinity. Saline soils occur in the river deltas in strip of land extending from few kilometers to $180 \mathrm{~km}$ from the coast. The flow of fresh water in the upstream river plays an important role to control the salinity intrusion. The upstream withdrawal of the Ganges water has reduced the flow tremendously and increased salinity in the tidal river, decreased surface water availability in the rivers and canals, lowered ground water table and reduced soil moisture content. About 1.02 million hectares in the coastal areas (out of 1.459 million hectares of cultivated land in the country) are affected by various degrees of salinity. Very slight salinity $\left(2.0-4.0 \mathrm{dS} \mathrm{m}{ }^{-1}\right)$ exists in about 0.282 million ha, slight salinity $\left(4.1-8.0 \mathrm{dS} \mathrm{m}^{-1}\right.$ in 0.297 million ha, moderate salinity (8.1-12.0 dS m$\left.{ }^{-1}\right)$ in 0.191 million ha, strong salinity (12.1-16.0 dS $\mathrm{m}^{-1}$ ) in 0.45 million hectares of land. About 0.087 million ha of coastal land is affected by very strong salinity $\left(>16.0 \mathrm{dS} \mathrm{m}^{-1}\right)$. The salinity varies considerably by seasons. In dry season soil and river water salinity increase, while during the monsoon season, it goes down. Therefore, land use also has temporal and spatial variation with season (Hussain, 2008). If salinity increases with time it is estimated that there will be reduction in production by $10 \%$ by 2050 (IPCC, 2007). Salinity in soils is characterized by the excess presence of sodium ions along with dominant anions like chlorine and sulfate which combine together to increased electrical conductivity (Ali et al., 2013). The effects of salinity on different parameters like morphological, physiological and biochemical traits have been studied in rice which showed reduced tillering, Although the genetics of salt tolerance is useful for the researchers to develop salt tolerant varieties, there are some problems those are required to be assessed. The main reason is that salinity is not uniformly distributed throughout a given area and thus it is difficult to recognize tolerant variety added that there are some variations which are found among species and some among cultivars within species (Arzani, 2008; Ashraf and Foolad, 2013).

Hydroponic system is perfectly compatible with screening. Moreover, assessment of genetic diversity and identification of superior genotypes are important as well as necessary for any crop improvement program (Bhuiyan, 2005). Molecular markers have been proved to be very useful for crop evaluation in many species. A rapid as well as technically simple method include SSR analysis which is based on PCR 
assay requiring only small quantity of DNA and thus inexpensive (Litt and Lutty, 1989). Through PCR different alleles at a locus can be detected by using conserved DNA sequence flanking SSR as primers. SSR have become a popular type of codominant molecular marker in genetic analysis and plant breeding application (Choi et al., 2003). Twenty rice genotypes of diverse origins were assessed to examine salt tolerance potentiality at seedling stage as well as to elucidate the genetic variation using SSR markers.

\section{MATERIALS AND METHODS}

This experiment was carried out both glass house and laboratory of the Biotechnology Division of Bangladesh Institute of Nuclear Agriculture (BINA), during the period from February 2019 to June 2019. Modified hydroponic system (Gregorio et al., 1997) was used at the glasshouse to evaluate salt tolerance of the 20 rice genotypes using Peter's solution (Yoshida et al., 1976).

The salinization levels were EC at $6 \mathrm{dS} \mathrm{m}^{-1}, 8 \mathrm{dS} \mathrm{m} \mathrm{m}^{-1}, 10 \mathrm{dS} \mathrm{m}$ and $12 \mathrm{dS} \mathrm{m}^{-1}$. The salinity level was measured through EC using the EC meter and maintained $\mathrm{pH}$ at 5.1 daily. Salt stresses were applied at $7^{\text {th }}$ days old seedling. The data were recorded at the age of 7 days, 14 days and 21 days, shoot length, root length and dry weight of them also recorded using SES range 3-9 (tolerant, moderately tolerant, susceptible and highly susceptible). The genotypes were evaluated using IRRI standard protocol (Gregorio et al., 1997).Plants were separately kept into envelops and oven dried at $72^{\circ} \mathrm{C}$ for a week and weighed.

Twenty-one days old seedlings were collected for the isolation of genomic DNA using the mini preparation Modified Cetyl Tri methyl Ammonium Bromide (CTAB) method (IRRI, 1988). The leaf samples were cut into $2-3 \mathrm{~cm}$ pieces and grounded. Extraction Buffer $(800 \mu \mathrm{l})$ and $20 \% \operatorname{SDS}(50 \mu \mathrm{l})$ were added, Vortexed for 20 seconds and incubated for 10 minutes at $65^{\circ} \mathrm{C}$ in the hot water bath, $100 \mu 15 \mathrm{M} \mathrm{NaCl}$ was added and inverted to suspend. Then $100 \mu \mathrm{CTAB}$ was added and vortexed for 20 seconds, incubated for 10 minutes at $65^{\circ} \mathrm{C}$, added $900 \mu \mathrm{l}$ chloroform mix; centrifuged at $15000 \mathrm{rpm}$ for 15 minutes. The supernatant was transferred into a new tube and added $600 \mu \mathrm{l}$ ice-cold is opropanol and the mixture centrifuged at 12000 rpm for 15 minutes. The pellet was then washed with $200 \mu 170 \%$ ethanol, centrifuge at $15000 \mathrm{rpm}$ for 5 minutes and allowed to air-dry, suspended in $30 \mu 11 \mathrm{X}$ TE buffer and stored at $-20{ }^{\circ} \mathrm{C}$. Thirteen primers were used for the analysis. The total volume of PCR cocktail was $9 \mu \mathrm{l}$ per sample and $1 \mu \mathrm{l}$ genomic DNA to make it $10 \mu \mathrm{l}$ and thus was ready for running in the DNA thermal cycler, The reaction mixture was preheated at $94^{\circ} \mathrm{C}$ for 5 minutes, denaturation at $94^{\circ} \mathrm{C}$ for 30 seconds and annealing at $55^{\circ} \mathrm{C}$ for 1 minute and polymerization reaction at $72^{\circ} \mathrm{C}$ for $1 \mathrm{~min}$ followed by 35 times repeating these cycles, incubated at $72^{\circ} \mathrm{C}$ for 5 minutes. After electrophoresis, the gel was soaked in ethidium bromide $(10 \mathrm{mg} / \mathrm{ml})$ solution for 12-15 minutes. High performance ultraviolet light box (UV trans-illuminator) of gel doc used for checking the DNA bands. The DNA was observed as band and the records were 
saved. The size (in nucleotide base pairs) of the amplified band for each microsatellite marker was determined based on its migration relative to a molecular weight size marker with the help of Alpha Ease FC 5.0 software. The summary statistics including the number of alleles per locus, major allele frequency, gene diversity and Polymorphism Information Content (PIC) values were determined using POWER MARKER version 3.23. Allele molecular weight data were exploited to determine the genetic distance for phylogeny reconstruction.

Table 1. List of SSR markers used for the exploring of genetic diversity of twenty diverse rice genotypes

\begin{tabular}{|c|c|c|c|c|c|c|}
\hline Marker & & Primer sequence (5'-3') & $\begin{array}{l}\text { Chromosome } \\
\text { no. }\end{array}$ & $\begin{array}{l}\text { Estimated } \\
\text { length } \\
\text { (bp) }\end{array}$ & Repeat motif & $\begin{array}{l}\text { Annealing } \\
\text { temp. }\left({ }^{\circ} \mathrm{C}\right)\end{array}$ \\
\hline RM17 & For. & TGCCCTGTTATTTTCTTCTCTC & 12 & 184 & $(\mathrm{GA})_{21}$ & 55 \\
\hline RM276 & $\begin{array}{l}\text { Rev. } \\
\text { For. } \\
\text { Rev. }\end{array}$ & $\begin{array}{l}\text { GGTGATCCTTTCCCATTTCA } \\
\text { CTCAACGTTGACACCTCGTG } \\
\text { TCCTCCATCGAGCAGTATCA }\end{array}$ & 6 & 149 & $(\mathrm{AG})_{8} \mathrm{~A}_{3}(\mathrm{GA})_{33}$ & 55 \\
\hline RM234 & $\begin{array}{l}\text { For. } \\
\text { Rev. }\end{array}$ & $\begin{array}{l}\text { ACAGTATCCAAGGCCCTGG } \\
\text { CACGTGAGACAAAGACGGAG }\end{array}$ & 7 & 156 & $(\mathrm{CT})_{25}$ & 55 \\
\hline RM302 & $\begin{array}{l}\text { For. } \\
\text { Rev. }\end{array}$ & $\begin{array}{l}\text { TGCAGGTAGAAATTGAAGC } \\
\text { AGTGGATGTTAGGTGTAACAGG }\end{array}$ & 1 & 156 & $(\mathrm{GT})_{30}(\mathrm{AT})_{8}$ & 55 \\
\hline RM310 & $\begin{array}{l}\text { For. } \\
\text { Rev. }\end{array}$ & $\begin{array}{l}\text { CCAAAACATTTAAAATATCATG } \\
\text { GCTTGTTGGTCATTACCATTC }\end{array}$ & 8 & 105 & $(\mathrm{CT})_{19}$ & 55 \\
\hline RM510 & $\begin{array}{l}\text { For. } \\
\text { Rev. }\end{array}$ & $\begin{array}{l}\text { AACCGGATTAGTTTCTCGCC } \\
\text { TGAGGACGACGAGCAGATTC }\end{array}$ & 6 & 122 & $(\mathrm{GA})_{15}$ & 55 \\
\hline RM223 & $\begin{array}{l}\text { For. } \\
\text { Rev. }\end{array}$ & $\begin{array}{l}\text { GAGTGAGCTTGGGCTGAAAC } \\
\text { GAGTGAGCTTGGGCTGAAAC }\end{array}$ & 8 & 165 & $(\mathrm{CT})_{25}$ & 55 \\
\hline RM493 & $\begin{array}{l}\text { For. } \\
\text { Rev. }\end{array}$ & $\begin{array}{l}\text { TAGCTCCAACAGGATCGACC } \\
\text { GTACGTAAACGCGGAAGGTG }\end{array}$ & 1 & 211 & $(\mathrm{CTT})_{9}$ & 55 \\
\hline RM435 & $\begin{array}{l}\text { For. } \\
\text { Rev. }\end{array}$ & $\begin{array}{l}\text { ATTACGTGCATGTCTGGCTG } \\
\text { CGTACCTGACCATGCATCTG }\end{array}$ & 6 & 166 & $(\mathrm{ATG})_{7}$ & 55 \\
\hline RM7075 & $\begin{array}{l}\text { For. } \\
\text { Rev. }\end{array}$ & $\begin{array}{l}\text { GCGTTGCAGCGGAATTTGTAGG } \\
\text { CCCTGCTTCTCTCGTGCAGAG }\end{array}$ & 1 & 155 & $(\mathrm{ACAT})_{13}$ & 55 \\
\hline RM208 & $\begin{array}{l}\text { For. } \\
\text { Rev. }\end{array}$ & $\begin{array}{l}\text { TCTGCAAGCCTTGTCTGATG } \\
\text { TAAGTCGATCATTGTGTGGACC }\end{array}$ & 2 & 173 & $(\mathrm{CT})_{17}$ & 55 \\
\hline RM8094 & $\begin{array}{l}\text { For. } \\
\text { Rev. }\end{array}$ & $\begin{array}{l}\text { AAGTTTGTACACATCGTATACA } \\
\text { CGCGACCAGTACTACTACTA }\end{array}$ & 1 & 209 & $(\mathrm{AT})_{31}$ & 55 \\
\hline RM562 & $\begin{array}{l}\text { For. } \\
\text { Rev. }\end{array}$ & $\begin{array}{l}\text { CACAACCCACAAACAGCAAG } \\
\text { CTTCCCCCAAAGTTTTAGCC }\end{array}$ & 1 & 243 & $(\mathrm{AAG})_{13}$ & 55 \\
\hline
\end{tabular}

\section{RESULTS AND DISCUSSIONS}

\section{Morphological characterization}

The salinity tolerance level for seven days old rice seedlings ranged from 3-9 in SES for 20 rice genotypes. Three rice genotypes, FL478, Pokkali, Binadhan-8 and Binadhan 10 showed high level of salinity tolerance obtaining the salinity tolerance level 3. Four rice genotypes, Sadamota, IR-4630, IR-64, and FR13A exhibited moderate salinity tolerance having the salinity tolerance level 5 . Ten rice cultivars, Binadhan-20, THDB, MV-20, Moulata, Dudkalam, Pot-18, Pot-27, BRRI-67, CPD- 
29, and CPD-23 were found susceptible to salt stress as they achieved 7 in salinity tolerance level. Finally, two genotypes of twenty rice genotypes, Binadhan-17, and Binadhan-21 showed huge sensitivity towards salt stress and thereby, grouped into highly susceptible category having the salinity tolerance level 9.

Salt stress affected the growth performance of 20 rice genotypes at different level during seedling stage. The modified standard evaluation system of visual salt injury was employed to characterize salt tolerance in 20 rice genotypes during their seedling stage in four salt stress treatments $\left(6 \mathrm{dS} \mathrm{m}^{-1}, 8 \mathrm{dS} \mathrm{m}^{-1}, 10 \mathrm{dS} \mathrm{m}^{-1}\right.$ and $12 \mathrm{dS}$ $\mathrm{m}^{-1}$ ). In terms of shoot length, the reduction percentage ranged from $40-65 \%$ compared with non-salinized rice cultivars in hydroponic system. In case of root length, the reduction percentage of different rice genotypes ranged from 2-34\% compared to control condition. Moreover, regarding this case some rice cultivars exhibited enlarged root compared to non-salinized rice genotypes. Besides, reduction in total dry matter (ranged from $44-87 \%$ ) was observed in most of the rice genotypes in comparison with the control condition. The level of reduction ranged from 44-87\% among 20 rice cultivars in their total dry matter. The modified standard evaluation system of visual salt injury was employed to characterize salt tolerance in 20 rice genotypes during their seedling stage in four salt stress treatment $\left(6 \mathrm{dS} \mathrm{m}^{-1}, 8 \mathrm{dS} \mathrm{m}^{-1}, 10 \mathrm{dS} \mathrm{m}{ }^{-1}\right.$ and $\left.12 \mathrm{dS} \mathrm{m}^{-1}\right)$. The findings in this study that the rice roots and shoots exhibited a significant reduction in their length, fresh weight and dry weight were consistent with Amirjani (2010) who reported that salt stress level decreased as the salt concentration increased in rice. Bhowmik et al. (2009) reported that plant height of tolerant lines of rice were reduced by $19 \%$ under salt stress (EC $12 \mathrm{dS} \mathrm{m}^{-1}$ ), whereas those of susceptible lines were reduced by $46 \%$. Due to variation of genotype the change also varied in different extent. Our study also complied with Bhuiyan (2005) who reported that salt stress suppresses the growth of leaves in the plants resulting in complete cessation of growth and development. Tatar et al. (2010) found that salt stress significantly reduced the total dry matter of rice cultivars which was similar to our findings. Senadhera et al. (2012) observed that the salt stress of $50 \mathrm{mM} \mathrm{NaCl}$ caused a significant decrease in both fresh weight and dry weight. These results were also compatible with the earlier findings (Dhar et al. 2012; Maiti et al. 2006). 


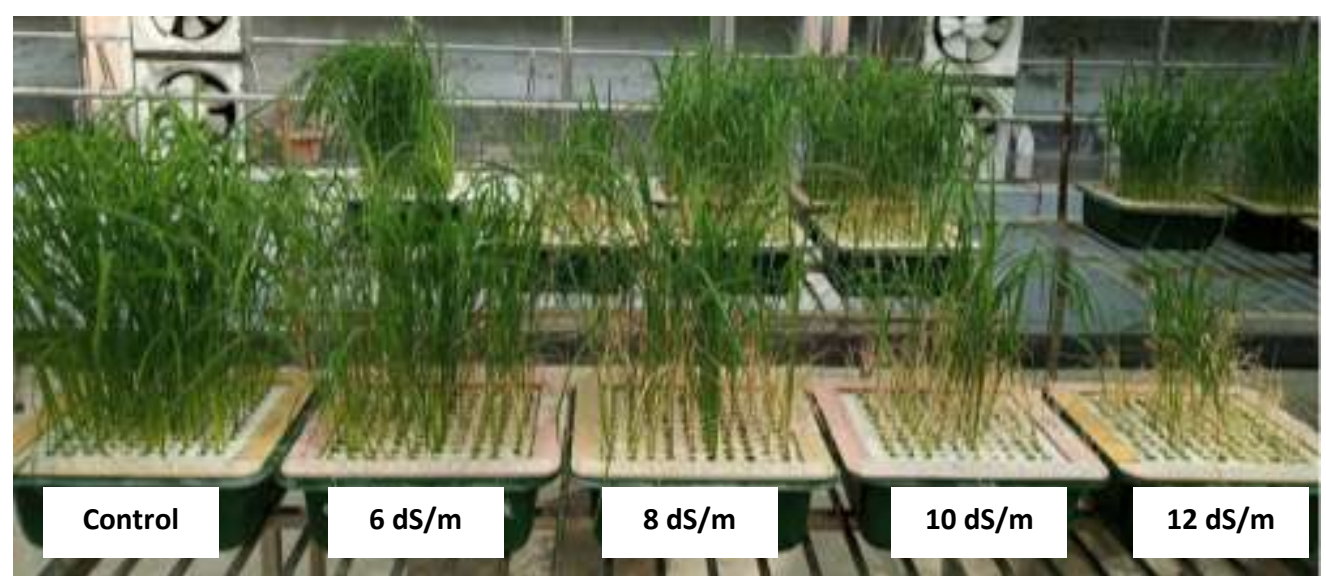

Figure 1. Morphological characterization of 20 rice genotypes at seedling stage at different salt stress conditions

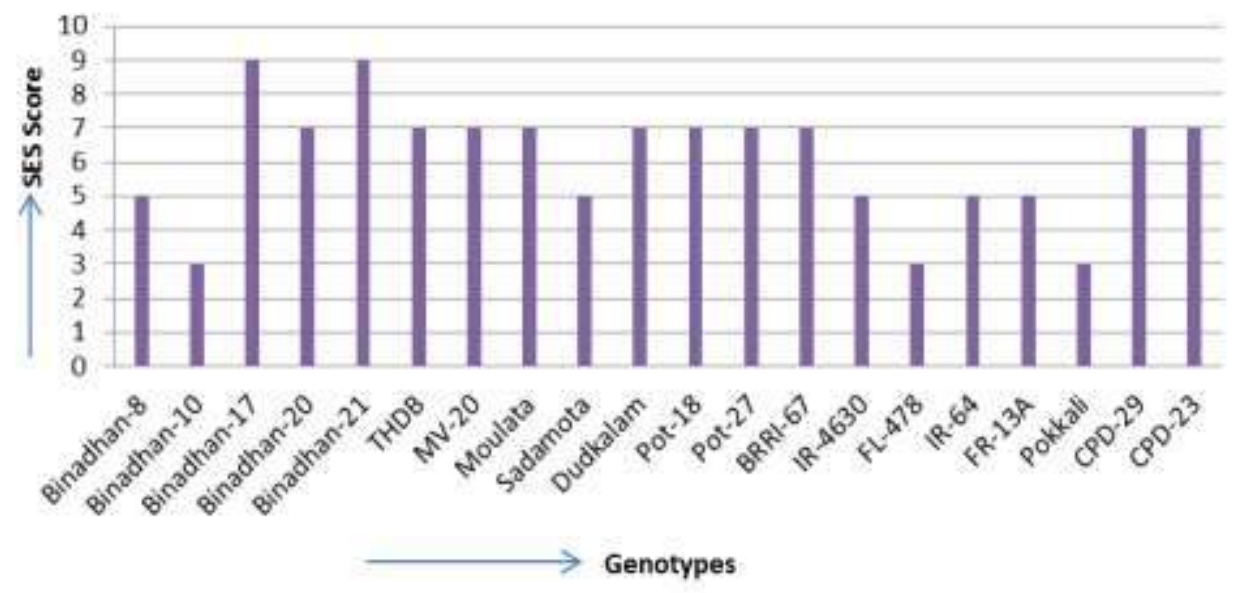

Figure 2. Standard evaluation scoring data chart of 20 rice genotypes 


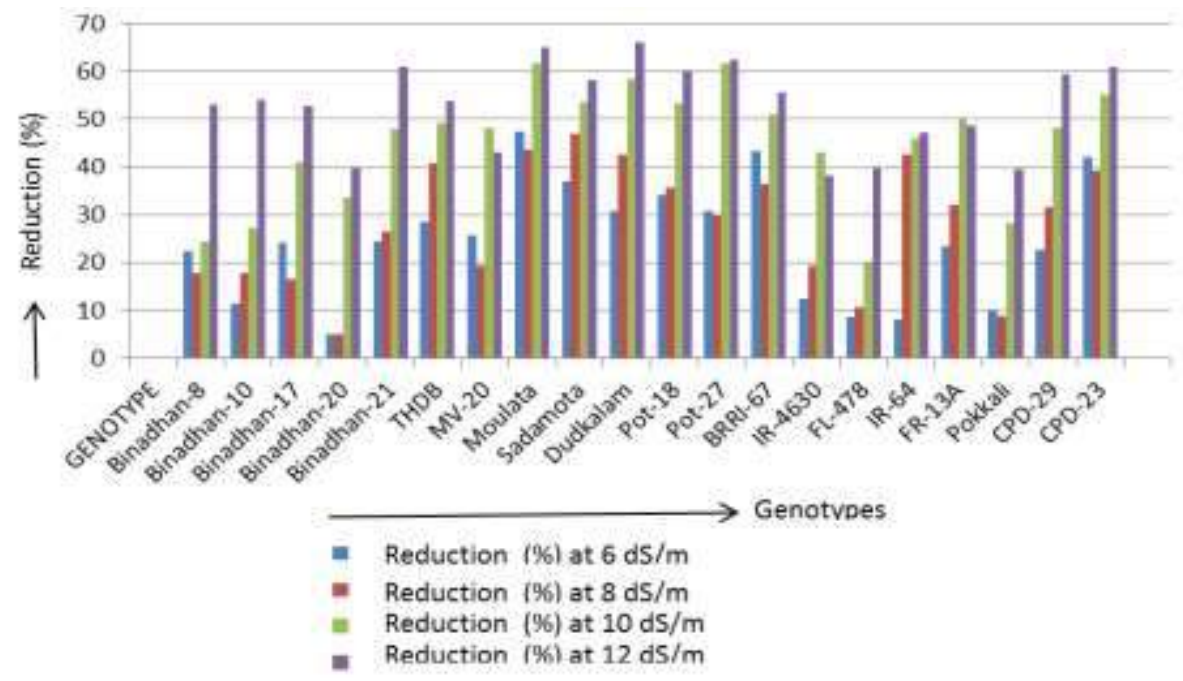

Figure 3. Graphical representation of reduction (\%) of shoot length

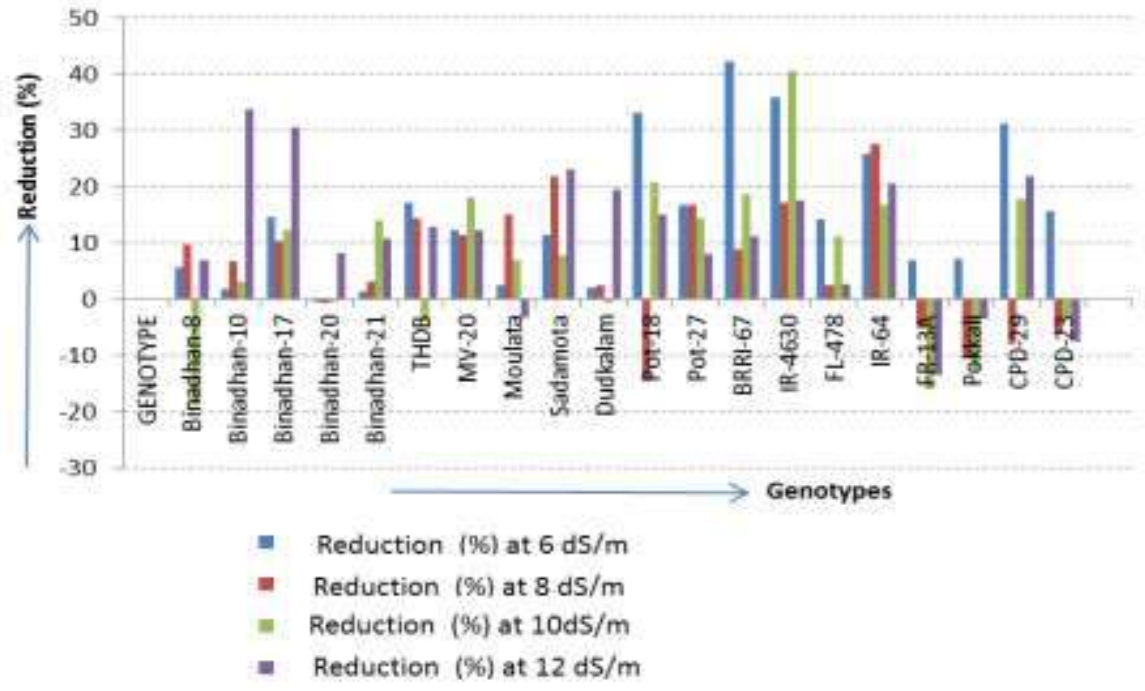

Figure 4. Graphical representation of reduction (\%) of root length 


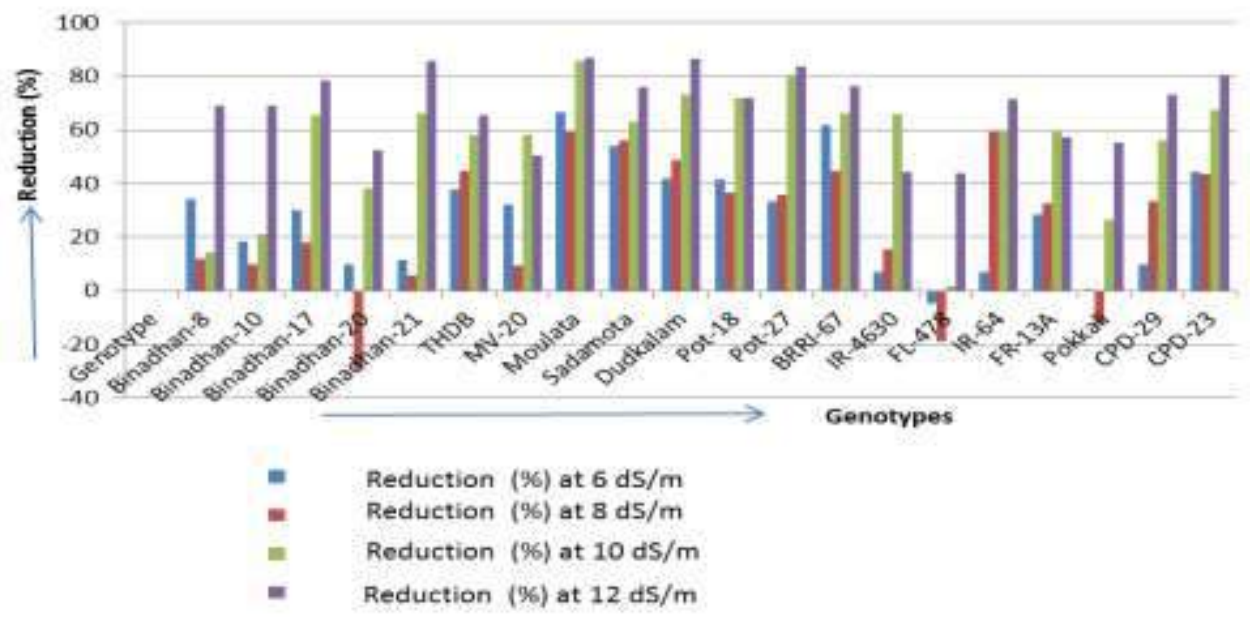

Figure 5. Graphical representation of reduction (\%) of dry weight

\section{Molecular characterization}

\section{Molecular characterization using SSR markers}

Twenty rice genotypes were analyzed exploiting 13 loci for SSR marker-based DNA fingerprinting technique. Amplified microsatellite loci were analyzed to find out polymorphism. and all the 13 microsatellite loci were polymorphic and had 4 alleles (mean) per locus. The bands obtained, were compared to the band of salt tolerant variety like Pokkali, FL478, Binadhan-10. In case of RM17, allele size ranged from 148-169bp, RM276, RM234, RM302, RM310, RM510, RM223, RM493, RM435, RM7075, RM208, RM8094 and RM562 displayed the range 99-138bp, 160-182bp, 146-178bp, 112-128bp, 112-119bp, 153-158bp, 178-207bp, 163-165bp, 148-188bp, 169-171bp, 190-225bp, 164-273bp respectively. Molecular marker helps to identify alleles that are associated with key phenotypic traits (Xu et al., 2004). In present study, all markers generated polymorphic banding patterns where a total of 53 alleles were detected across the genotypes with an average of 4 alleles per locus which was compatible with the previous work of Dhar et al. (2012).The number of alleles detected is one of the selection categories in assessing a marker's usefulness in diversity analyses since a higher allele count per locus means that the marker is able to discriminate genotypes that might be indistinguishable to other markers (Seetharam et al., 2009).The size of various major alleles at different loci ranges from $99 \mathrm{bp}$ (RM276) to $273 \mathrm{bp}$ (RM562). Among all the genotypes, on an average, $46 \%$ of them shared a common major allele ranging from $25 \%$ (RM276) to $75 \%$ (RM435) at each locus. The highest gene diversity (0.81) was observed in RM276 and the lowest gene diversity (0.41) was observed in RM17 and RM435, having an average diversity of 0.63 . In present study gene diversity at each SSR locus was 
significantly correlated with the number of alleles detected, number of repeat motif and with the allele size range. This result is consistent with previous work done by Heenan et al. (2000). PIC value of each marker can be determined on the basis of its allele. PIC varied significantly for all the studied SSR loci. In this study, the level of polymorphism among 20 rice genotypes was evaluated by calculating PIC values for each of the 13 SSR loci. The PIC values ranged from 0.37 to 0.78 having an average of 0.58 per locus. The highest PIC value was 0.78 for RM276 and the lowest value was 0.37 for RM17 and RM435.PIC value is reflective of the number of detected alleles and the relative distribution of their frequency. A higher PIC value is favored since a low PIC value is indicative of either a low number of detected alleles, or that the alleles are distributed unequally among the genotypes or both. In all three cases, the result is a marker with a poor ability to discriminate between genotypes. According to Jiang et al. (2010), a PIC value of greater than 0.5 is reflective of a good marker. The marker RM276 attained the highest PIC value (0.78), while RM435 obtained the lowest PIC value (0.41) in our study.
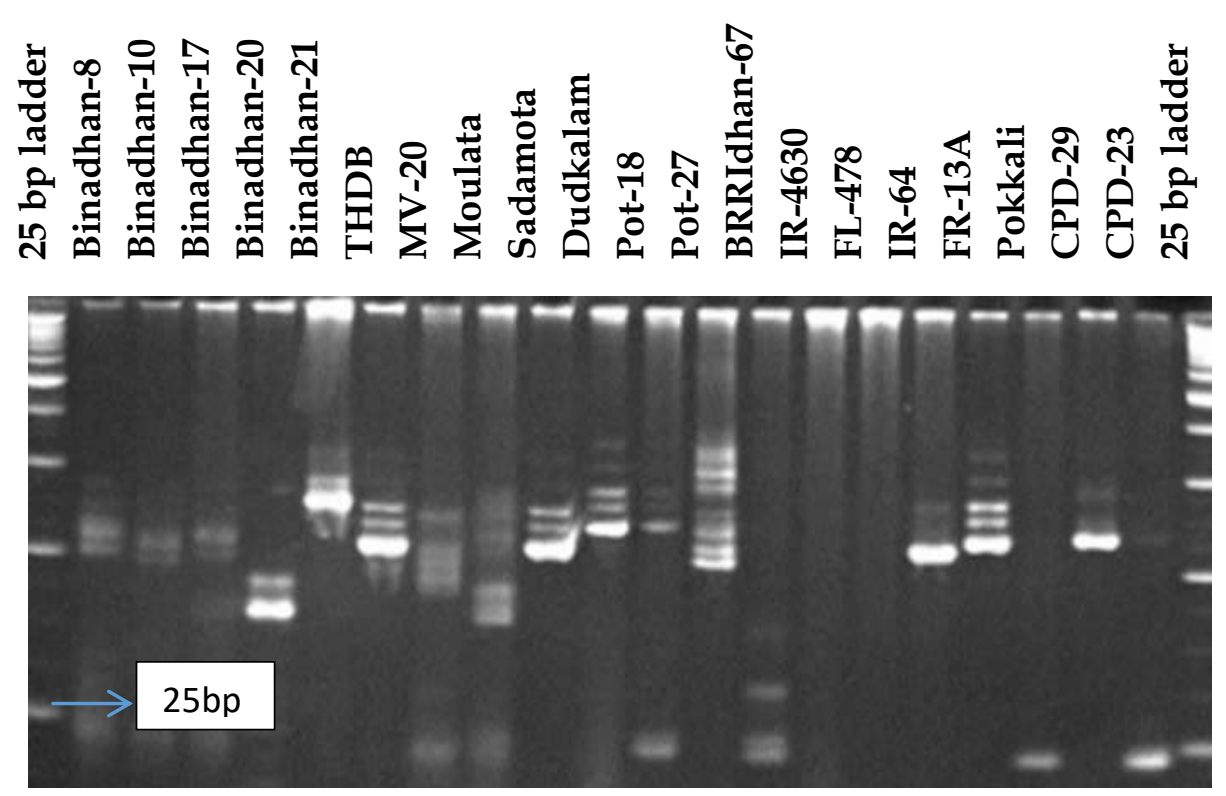

Figure 6. Microsatellite profiles of 20 rice genotypes at locus RM234 

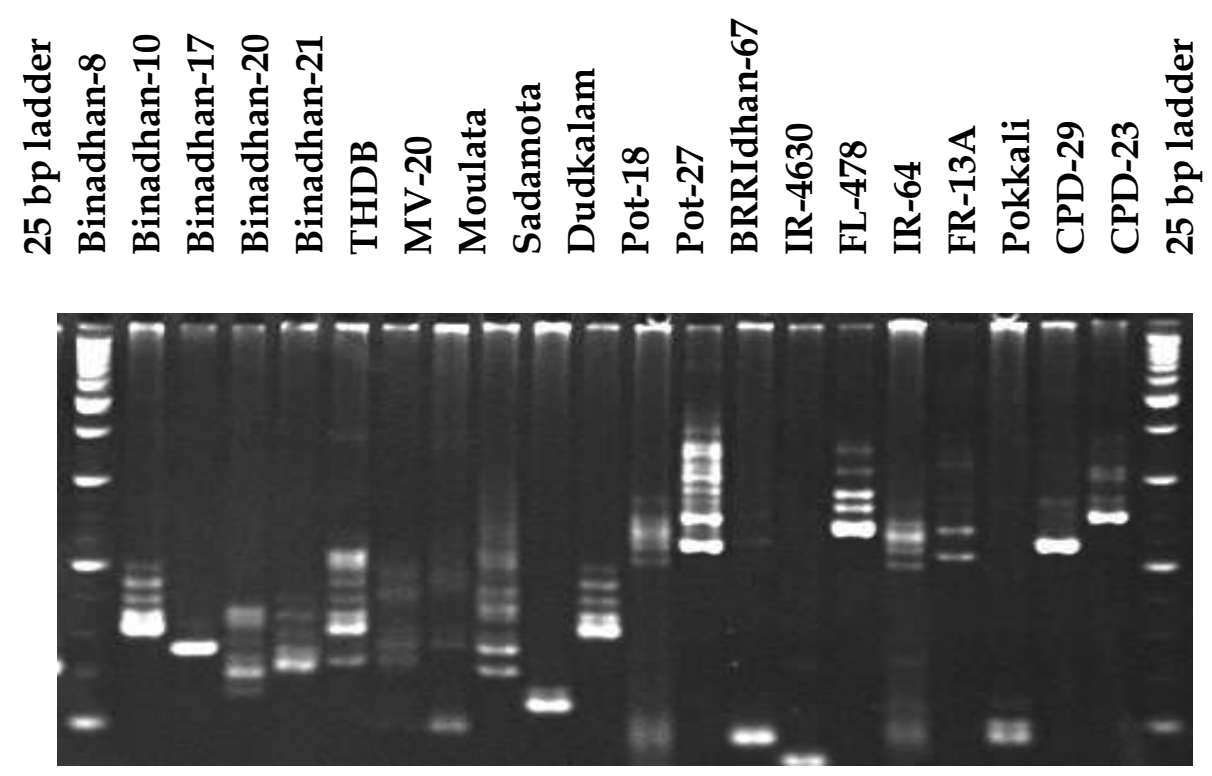

Figure 7. Microsatellite profiles of 20 rice genotypes at locus RM276

Table 2. Data of sample size, major alleles, gene diversity and PIC value

\begin{tabular}{llllll}
\hline Marker & \multicolumn{2}{c}{ Major Allele } & Allele No & Gene Diversity & PIC \\
& Size $(\mathrm{bp})$ & Frequency $(\%)$ & & & \\
\hline RM17 & 169 & 75 & 3 & $\mathbf{0 . 4 1}$ & 0.37 \\
RM276 & 135 & 25 & 6 & $\mathbf{0 . 8 1}$ & $\mathbf{0 . 7 8}$ \\
RM234 & 173 & 45 & 4 & 0.70 & 0.65 \\
RM302 & 148 & 30 & 5 & 0.76 & 0.72 \\
RM310 & 112 & 45 & 4 & 0.67 & 0.60 \\
RM510 & 112 & 70 & 3 & 0.46 & 0.41 \\
RM223 & 158 & 35 & 3 & 0.66 & 0.58 \\
RM493 & 178 & 30 & 4 & 0.68 & 0.62 \\
RM435 & 165 & 75 & 3 & $\mathbf{0 . 4 1}$ & $\mathbf{0 . 3 7}$ \\
RM7075 & 165 & 40 & 6 & 0.74 & 0.70 \\
RM208 & 171 & 65 & 3 & 0.52 & 0.46 \\
RM8094 & 190 & 40 & 4 & 0.70 & 0.65 \\
RM562 & 273 & 25 & 5 & 0.73 & 0.68 \\
Mean & & 46 & 4 & $\mathbf{0 . 6 3}$ & $\mathbf{0 . 5 8}$ \\
\hline
\end{tabular}


Table 3. Summary of genetic distance values among 20 rice genotypes using 13 SSR markers

\begin{tabular}{|c|c|c|c|c|c|c|c|c|c|c|c|c|c|c|c|c|c|c|c|c|}
\hline Gen.* & $\mathrm{P} 1$ & $\mathrm{P} 2$ & P3 & $\mathrm{P} 4$ & P5 & P6 & P7 & P8 & P9 & $\mathrm{P} 10$ & $\mathrm{P} 11$ & $\mathrm{P} 12$ & P13 & P14 & $\mathrm{P} 15$ & P16 & $\mathrm{P} 17$ & P18 & P19 & P20 \\
\hline $\mathrm{P} 1$ & 0.00 & 0.69 & 0.54 & 0.69 & 0.15 & 0.77 & 0.85 & 0.69 & 0.92 & 0.31 & 0.77 & 0.69 & 0.77 & 0.69 & 0.85 & 0.23 & 0.54 & 0.69 & 0.77 & 0.77 \\
\hline $\mathrm{P} 2$ & & 0.00 & 0.46 & 0.46 & 0.62 & 0.23 & 0.77 & 0.77 & 0.62 & 0.54 & 0.62 & 0.69 & 0.77 & 0.46 & 0.62 & 0.62 & 0.85 & 0.85 & 0.62 & 0.38 \\
\hline P3 & & & 0.00 & 0.54 & 0.54 & 0.46 & 0.62 & 0.62 & 0.85 & 0.46 & 0.54 & 0.54 & 0.54 & 0.62 & 0.62 & 0.54 & 0.69 & 0.77 & 0.38 & 0.54 \\
\hline P4 & & & & 0.00 & 0.62 & 0.46 & 0.77 & 0.77 & 0.62 & 0.54 & 0.54 & 0.62 & 0.69 & 0.54 & 0.54 & 0.69 & 0.77 & 0.77 & 0.62 & 0.54 \\
\hline P5 & & & & & 0.00 & 0.69 & 0.92 & 0.77 & 0.77 & 0.15 & 0.69 & 0.77 & 0.69 & 0.69 & 0.85 & 0.08 & 0.62 & 0.77 & 0.77 & 0.69 \\
\hline P6 & & & & & & 0.00 & 0.77 & 0.77 & 0.69 & 0.62 & 0.54 & 0.69 & 0.62 & 0.54 & 0.69 & 0.69 & 0.85 & 0.85 & 0.69 & 0.54 \\
\hline P7 & & & & & & & 0.00 & 0.31 & 0.92 & 0.85 & 0.46 & 0.23 & 0.85 & 0.85 & 0.77 & 0.85 & 0.85 & 0.92 & 0.46 & 0.85 \\
\hline P8 & & & & & & & & 0.00 & 1.00 & 0.85 & 0.46 & 0.23 & 0.77 & 0.85 & 0.85 & 0.69 & 0.92 & 0.85 & 0.38 & 0.85 \\
\hline P9 & & & & & & & & & 0.00 & 0.69 & 0.77 & 0.92 & 0.69 & 0.62 & 0.92 & 0.77 & 0.62 & 0.54 & 0.92 & 0.54 \\
\hline P10 & & & & & & & & & & 0.00 & 0.62 & 0.69 & 0.69 & 0.62 & 0.85 & 0.23 & 0.62 & 0.69 & 0.69 & 0.62 \\
\hline P11 & & & & & & & & & & & 0.00 & 0.23 & 0.77 & 0.69 & 0.85 & 0.77 & 0.69 & 0.69 & 0.46 & 0.62 \\
\hline P12 & & & & & & & & & & & & 0.00 & 0.77 & 0.77 & 0.85 & 0.85 & 0.77 & 0.77 & 0.38 & 0.77 \\
\hline P13 & & & & & & & & & & & & & 0.00 & 0.77 & 0.62 & 0.69 & 0.77 & 0.85 & 0.69 & 0.69 \\
\hline P14 & & & & & & & & & & & & & & 0.00 & 0.54 & 0.69 & 0.77 & 0.77 & 0.77 & 0.46 \\
\hline P15 & & & & & & & & & & & & & & & 0.00 & 0.85 & 0.85 & 0.92 & 0.77 & 0.62 \\
\hline P16 & & & & & & & & & & & & & & & & 0.00 & 0.69 & 0.85 & 0.69 & 0.69 \\
\hline P17 & & & & & & & & & & & & & & & & & 0.00 & 0.23 & 0.69 & 0.69 \\
\hline P18 & & & & & & & & & & & & & & & & & & 0.00 & 0.77 & 0.62 \\
\hline P19 & & & & & & & & & & & & & & & & & & & 0.00 & 0.77 \\
\hline P20 & & & & & & & & & & & & & & & & & & & & 0.00 \\
\hline
\end{tabular}

Here, P1=Binadhan-8, P2=Binadhan-10, P3=Binadhan-17, P4=Binadhan-20, P5=Binadhan-21, P6=THDB, P7=MV-20, P8=Moulata, P9=Sadamota, P10=Dudkalam, P11=Pot-18, P12=Pot-27, P13=BRRI-67,P14=IR-4630, P15=FL-478, P16=IR-64,P17=FR-13A, P18=Pokkali, P19=CPD-29, P20=CPD-23.

Gen.*= Genotypes used in this study. 
Dendogram based on Nei's (1973) genetic distance using Unweighted Pair Group Method of Arithmetic Means (UPGMA) indicated differentiation of the 20 rice genotypes by 13 markers. All the 20 rice genotypes could be easily distinguished. The UPGMA cluster analysis led to the grouping of 20 rice genotypes in three major clusters at $40 \%$ cut off.

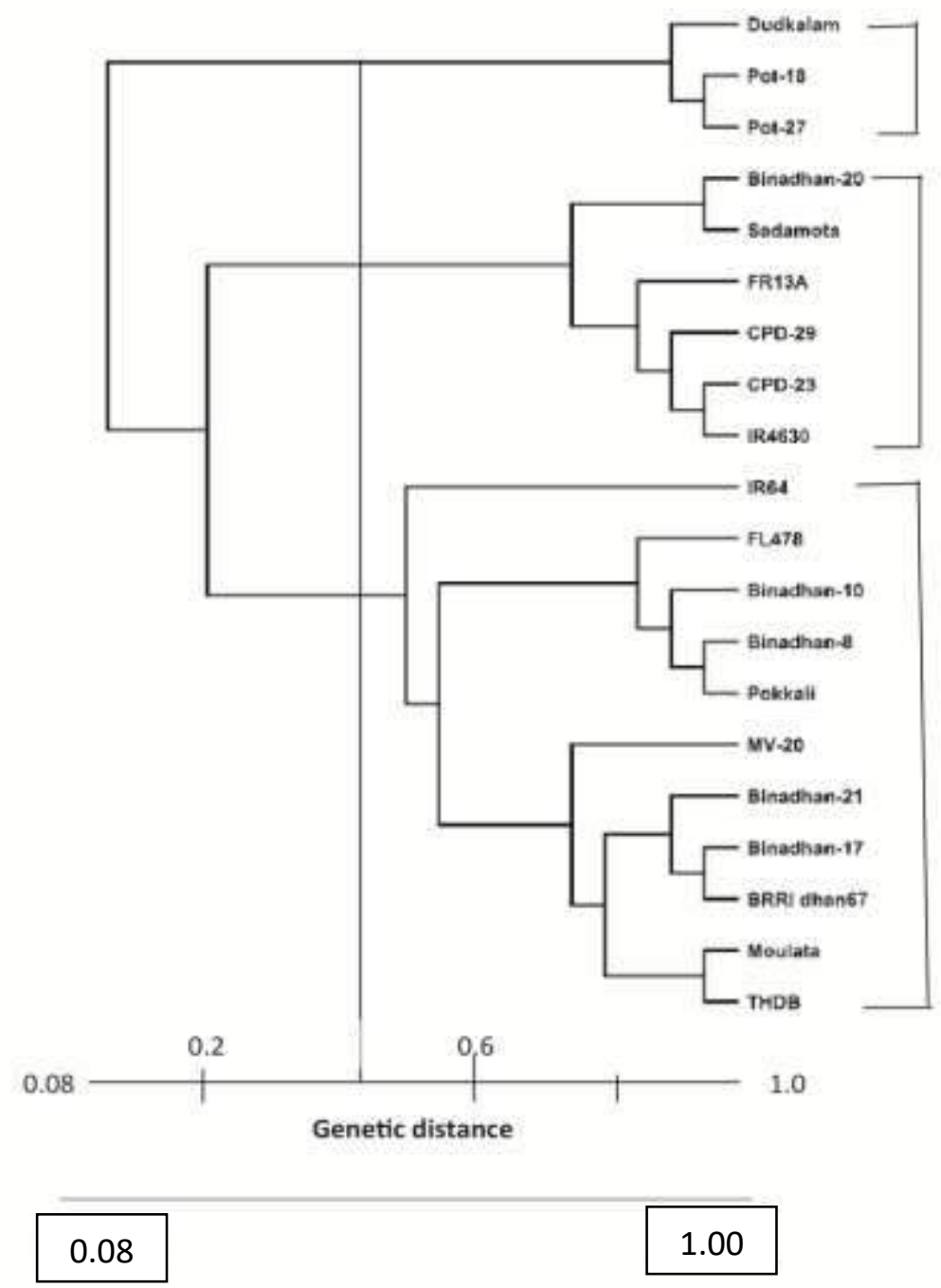

Figure 8. UPGMA Dendogram based on Nei's genetic distance according to SSR analysis 


\section{CONCLUSION}

The significant changes in morphological characteristics of 20 rice genotypes were revealed when applied to salt stress as compared to control condition, 3 genotypes were found as salt stress tolerant lines, 5 genotypes were found as moderately tolerant, 10 genotypes were found as susceptible and 2 genotypes were highly susceptible to salinity. At molecular level, significant differences in the numbers of alleles per locus were perceived; there were significant variation in their allele frequency and also significant differences in gene diversity as well as PIC value. The UPGMA dendogram showed 3 major clusters where phenotypic ally explored salt tolerant genotypes fall into different group opening a huge possibility of exploiting such diverse lines for future breeding program. Based on the revealed data set, it is obvious that Binadhan-8, Binadhan-10, Pokkali, Shadamota followed by FL478, IR64, IR4630, FR13A and possessing moderate potentiality at seedling stage can be used to develop salt tolerant varieties and all these genotypes is potential sources of tolerance and hybridization program for generating new salt tolerant genotype, construction of mapping population with a view to dissect the genetic architecture of salt tolerance followed by cloning of candidate gene and maker assisted introgression of such gene.

\section{Conflict of interest}

The authors declare that there is no conflict of interest.

\section{REFERENCES}

Ali, S., Gautam, R.K., Mahajan, R., Krishnamurthy, S.L., Sharma, S.K., Singh, R.K. and Ismail, A.M. (2013). Stress indices and selectable traits in Saltol QTL introgressed rice genotypes for reproductive stage tolerance to sodicity and salinity stresses. Field Crops Research, 154:65-73.

Amirjani, M.R. (2010). Effect of $\mathrm{NaCl}$ on some physiological parameters of rice. European Journal of Biological Science, 3:6-16.

Arzani, A. (2008). Improving salinity tolerance in crop plants: A Biotechnological View. In Vitro Cellular and Developmental Biology - Plant, 44(5):373383.

Ashraf, M. and Foolad, M. (2013). Crop breeding for salt tolerance in the era of molecular markers and marker assisted selection. Plant Breeding, 132:1020.

Bhowmik, S.K., Titov, S., Islam, M.M., Siddika, A., Sultana, S. and Haque, M.D.S. (2009). Phenotypic and genotypic screening of rice genotypes at seedling stage for salt tolerance. Journal of Biotechnology and Biochemistry, 4(2):126-131.

Bhuiyan, M.A.R. (2005). Efficiency in evaluating salt tolerance in rice using phenotypic and marker assisted selection. MS Thesis. Department of 
Genetics and Plant Breeding, Bangladesh Agricultural University, Mymensingh-2202, Bangladesh. Pp. 96.

Choi, W.Y., Lee, K.S., Ko, J.C., Choi, S.Y., Choi, D.Y. and Kim, T.S. (2003). Critical concentration of saline water for rice cultivation on a reclaimed coastal soil in Korea. International Rice Research Notes, 28(1):54-55.

Dhar, P., Ashrafuzzaman, M., Begum, S.N., Islam, M.M. and Chowdhury, M.M.H. (2012). Identification of salt tolerant rice genotypes and their genetic diversity analysis using SSR marker. International Journal of Bioscience, 2(9):45-50.

Gregorio, G.B., Senadhira, D. and Mendoza, R.T. (1997). Screening rice for salinity tolerance. IRRI discussion paper series 22. IRRI, Manila 30.

Heenan, D.P., Lewin, L.G. and McCaffery, D.W. (2000). Salinity tolerance in rice varieties at different growth stages. Australian Journal of Experimental Agriculture, 28(3):343-349.

Hussain, S.G. (2008). Livelihood Development through Agriculture in the Saline Prone Coastal Ecosystem. Bangladesh Agricultural Research Council. Pp. 1-32

IPCC. (2007). Climate change in Asia too alarming to contemplate. Intergovernmental panel on climate change. Pp. 85

IRRI. (2013). World rice statistics. Los Banos, Laguna, Philippines.

Jiang, S., Huang, C., Zhang, X., Wang, J., Chen, W. and Xu, Z. (2010). Development of a highly informative microsatellite (SSR) marker framework for rice (Oryza sativa) genotyping. Agricultural Sciences in China, 9:1697-1704.

Litt, M. and Lutly, J.A. (1989). A hyper variable microsatellite revealed by in vitro amplification of a dinucleotide repeat within the cardiac muscle actingene. The American Journal of Human Genetics, 44:397-401.

Mamun, A., Sarker, P. and Noor, M.M. (2019). Influence of irrigation and gypsum on wheat cultivation in saline soil. Research in Agriculture, Livestock and Fisheries, 6(1):1-10.

Maiti, R.K. Vidyasagar, P. and Banerjee, P.P. (2006). Salinity tolerance in rice $(O$. sativa) hybrids and their parents at emergence and seedling stage. Crop Research, 31(3):427-433.

Mohammadi-Nejad, G., Singh, R.K., Arzani, A., Rezaiec, A.M., Sabourid, H. and Gregorio, G.B. (2010). Evaluation of Salinity Tolerance in Rice Genotypes. International Journal of Plant Production, 4(3):199-208.

Negrao, S., Courtois, B., Ahmadi, N., Abreu, I., Saibo, N. and Oliveira, M.M. (2011). Recent updates on salinity stress in rice: from physiological to molecular responses. Critical Reviews in Plant Sciences, 30:329-377. 
Seetharam, K., Thirumeni, S. and Paramasivam, K. (2009). Estimation of genetic diversity in rice $(O$. sativa $)$ genotypes using SSR markers and morphological characters. African Journal of Biotechnology, 8(10):20502059.

Senadheera, P. Tirimanne, S. and Maathuis, F.J.M. (2012). Long term salinity stress reveals variety specific differences in root oxidative stress response. Rice Science, 19(1):36-43.

Shelly, I.J., Takahashi-Nosaka, M., Kano-Nakata, M., Haque, M.S. and Inukai, Y. (2016). Rice cultivation in Bangladesh: present scenario, problems, and prospects. Journal of International Cooperation for Agricultural Development, 14:20-29.

Tatar, O., Brueck, H., Gevrek, M.N. and Asch, F. (2010). Physiological responses of two Turkish rice (Oryza sativaL.) varieties to salinity. Turkish Journal of Agriculture and Forestry, 34:451-459.

$\mathrm{Xu}$, Y., Beachell, H. and McCouch, S.R. (2004). Marker based approach to broadening the genetic base of rice in the USA. Crop Science, 44:19471959.

Yoshida, S., Forno, D.A., Cock, J.H. and Gomez, K.A. (1976). Laboratory manual for physiological studies of rice. IRRI, Las Banos, Laguna 83. 